\title{
Ionophore-based potentiometric PVC membrane sensors for determination of phenobarbitone in pharmaceutical formulations
}

\author{
HAITHAM ALRABIAH ${ }^{1}$ \\ ABDULRAHMAN AL-MAJED ${ }^{1}$ \\ MOHAMMED ABOUNASSIF ${ }^{1}$ \\ GAMAL A.E. MOSTAFA ${ }^{1,2 *}$ \\ ${ }^{1}$ Pharmaceutical Chemistry \\ Department, College of Pharmacy \\ King Saud University \\ P.O.Box 2457, Riyadh 11451 \\ Saudi Arabia \\ ${ }^{2}$ Micro-Analytical Laboratory \\ Applied Organic Chemistry \\ Department, National Research Center \\ Doki, Cairo, Egypt
}

\begin{abstract}
The fabrication and development of two polyvinyl chloride (PVC) membrane sensors for assaying phenobarbitone sodium are described. Sensors 1 and 2 were fabricated utilizing $\beta$ - or $\gamma$-cyclodextrin as ionophore in the presence of tridodecylmethylammonium chloride as a membrane additive, and PVC and dioctyl phthalate as plasticizer. The analytical parameters of both sensors were evaluated according to the IUPAC guidelines. The proposed sensors showed rapid, stable anionic response ( -59.1 and $-62.0 \mathrm{mV}$ per decade) over a relatively wide phenobarbitone concentration range $\left(5.0 \times 10^{-6}-1 \times 10^{-2}\right.$ and $\left.8 \times 10^{-6}-1 \times 10^{-2} \mathrm{~mol} \mathrm{~L}^{-1}\right)$ in the $\mathrm{pH}$ range of $9-11$. The limit of detection was $3.5 \times 10^{-6}$ and $7.0 \times 10^{-6} \mathrm{~mol} \mathrm{~L}^{-1}$ for sensors 1 and 2, respectively. The fabricated sensors showed high selectivity for phenobarbitone over the investigated foreign species. An average recovery of $2.54 \mu \mathrm{g} \mathrm{mL} \mathrm{m}^{-1}$ phenobarbitone sodium was 97.4 and $101.1 \%$, while the mean relative standard deviation was 3.0 and $2.1 \%$, for sensors 1 and 2, respectively. The results acquired for determination of phenobarbitone in its dosage forms utilizing the proposed sensors are in good agreement with those obtained by the British Pharmacopoeial method.
\end{abstract}

Keywords: phenobarbitone sodium, membrane selective electrode, $\beta$-cyclodextrin, $\gamma$-cyclodextrin, PVC, potentiometry

Phenobarbitone is mostly utilized as an anticonvulsant with minimum requirements of medical care (1). Its chemical structure is 5-ethyl-5-phenyl-1,3-diazinane-2,4,6-trione. Developed countries use phenobarbitone medication for the treatment of epilepsy (2) as recommended by the World Health Organization. It is also used in the treatment of seizures in children (3). Phenobarbitone is also used to treat sleeping disorders, anxiety and drug withdrawal (1).

Spectrophotometry (4), chemiluminescence (5), conductometry (6), voltammetry (7), high performance liquid chromatography (HPLC-UV) $(4,8,9)$, gas chromatography (GC)

\footnotetext{
*Correspondence; e-mail: gamal_most@yahoo.com
} 


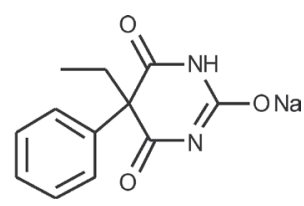

Fig. 1. Chemical structure of phenobarbitone sodium, $\mathrm{C}_{12} \mathrm{H}_{11} \mathrm{~N}_{2} \mathrm{NaO}_{3}, M_{\mathrm{r}} 254.22$.

$(10,11)$, GC-MS $(12,13)$ and capillary electrophoresis (14) have been cited in the literature as analytical techniques for phenobarbitone determination. On the other hand, the vast majority of these techniques include tedious, sophisticated instruments, complicated procedures and require highly qualified personnel. Potentiometric sensors based on PVC membrane are simple, rapid, sensitive and economical and are applied as analytical tools in different areas (15-17).

Only one potentiometric sensor for phenobarbitone has been cited (18). The cited method was based on the use of phenobarbitone-tetraoctylammonium ion-pair in the PVC membrane sensor (18). The calibration range was $1 \times 10^{-1}$ to $2 \times 10^{-4} \mathrm{~mol} \mathrm{~L}^{-1}$.

Cyclodextrins are widely used in different areas, especially in preparation of chemical sensors (19), due to their complexation properties (20,21). Cyclodextrin has a cage-like supramolecular structure that enables inclusion complex formation between the host cavity (seven and eight membered ring cavity, respectively, for $\beta$ - and $\gamma$-CD) and the guest. The main driving forces for inclusion complexes include van der Waals interactions, hydrophobic interactions, hydrogen bonding between the polar groups of guest molecules and the CDs hydroxyl groups and electrostatic interactions for ionic guests $(20,21)$.

The present study describes two new potentiometric membrane sensors for the assay of phenobarbitone in pharmaceuitical formulations based on the use of $\beta$ - (sensor 1 ) and $\gamma$-cyclodextrin (sensor 2) as sensing matrial in the PVC matrix.

\section{EXPERIMENTAL}

\section{Apparatus}

A pH/mV meter (model 523) (WTW, Germany), utilizing a phenobarbitone membrane sensor in conjunction with an Orion double junction $\mathrm{Ag} / \mathrm{AgCl}$ reference electrode (model 90-02) (Thermo, USA) containing $10 \%(\mathrm{~m} / \mathrm{V})$ potassium nitrate in the external compartment, was utilized for potentiometric measurements. All $\mathrm{pH}$ measurements were done using a combined Ross glass $\mathrm{pH}$ electrode (Thermo). All potentiometric assays were carried out at $25 \pm 1{ }^{\circ} \mathrm{C}$.

\section{Reagents and materials}

High molecular mass polyvinyl chloride powder (PVC), dibutyl sebacate (DBS), dioctyl phthalate (DOP), o-nitrophenyl octylether (NPOE) and tetrahydrofuran (THF) (purity $>99 \%$ ) were obtained from Aldrich Chemical Company (Germany). Phenobarbitone sodium was obtained from Sigma Chemical Company (Germany). Tridodecylmethylam- 
monium chloride (TDMACl) and cyclodextrins ( $\beta$-CD and $\gamma$-CD) were obtained from Aldrich (Switzerland). Phenobarbital sodium injection $200 \mathrm{mg} \mathrm{mL}^{-1}$ was from BDH (UK). All chemicals and reagents were of analytical reagent grade and doubly distilled water was used.

\section{Preparation of standard solutions}

The stock solution of phenobarbitone sodium $\left(1 \times 10^{-2} \mathrm{~mol} \mathrm{~L}^{-1}\right)$ was prepared by dissolving an appropriate amount of phenobarbitone in water. Working solutions were prepared by suitable dilution with water. The concentration range was from $1 \times 10^{-2}$ to $1 \times 10^{-6} \mathrm{~mol} \mathrm{~L}^{-1}$.

\section{Fabrication of phenobarbitone PVC membrane sensors}

In a glass Petri dish ( $5 \mathrm{~cm}$ in diameter), $0.35 \mathrm{~mL}$ of DBS or DOP or NPOE, $5 \mathrm{mg}$ of TDMACl and $190 \mathrm{mg}$ of PVC powder was added, mixed well, and then $10 \mathrm{mg}$ of $\beta$ - or $\gamma-C D$ was added. After mixing, $5.0 \mathrm{~mL}$ THF was added. After the solvent was allowed to evaporate overnight, the sensing PVC membrane was shaped. The PVC membrane was cut with a stopper borer $(10 \mathrm{~mm}$ inner size $)$ and stuck to a polyethylene tube $(3 \mathrm{~cm}$ length, 8 $\mathrm{mm}$ i.d.) using THF. The electrode body used comprised a glass tube, to whose end the polyethylene tube was attached. A PVC membrane disk of $1 \mathrm{~cm}$ was attached to the polyethylene tube. The inner solution of the working electrode contained equal volumes of $1 \times 10^{-2} \mathrm{~mol} \mathrm{~L}^{-1}$ phenobarbitone and $1 \times 10^{-2} \mathrm{~mol} \mathrm{~L}^{-1} \mathrm{KCl}(22,23)$. An inner reference electrode of $\mathrm{Ag} / \mathrm{AgCl}$ type was used. The indicator electrode was soaked in phenobarbitone solution when not in use.

\section{Sensor calibration}

The phenobarbitone PVC sensors were calibrated by inserting them, together with the reference electrode, in a 50-mL measuring cell containing $9.0 \mathrm{~mL}$ of $1 \times 10^{-2} \mathrm{~mol} \mathrm{~L}^{-1}$ sodium sulphate. One-mL aliquot of phenobarbitone solution was added and equilibrated under continuous stirring, to give the final phenobarbitone concentration from $1 \times 10^{-2}$ to $1 \times 10^{-6} \mathrm{~mol} \mathrm{~L}^{-1}$. The potential was recorded after adjustment to $\pm 1 \mathrm{mV}$ and the calibration curve was obtained by plotting the recorded potential against the negative logarithm of phenobarbitone concentration. It was utilized for the determination of unknown phenobarbitone.

\section{Determination of phenobarbitone}

Five $\mathrm{mL}$ of Phenobarbital sodium ${ }^{\circledR}$ injection, $200 \mathrm{mg} \mathrm{mL}^{-1}$, were transferred into a 50 -mL measuring flask and completed to the mark with water and then further diluted 10 times with $1 \times 10^{-2} \mathrm{~mol} \mathrm{~L}^{-1}$ sodium sulphate. The expected final concentration was $2 \mathrm{mg} \mathrm{mL}^{-1}$. The potential of the resulting solution was recorded using developed sensors and the concentration was calculated from the calibration curve.

Synthetic laboratory powder was prepared by addition of a known amount of phenobarbitone powder $(10 \mathrm{mg})$ to the mixture of excipients (magnesium stearate, glucose, lactose monohydrate, starch, microcrystalline cellulose $(240 \mathrm{mg})$. The whole powder mass $(250 \mathrm{mg})$ was completely dissolved in water $(\sim 50 \mathrm{~mL})$ with sonication for about 10 $\mathrm{min}$. The solution was filtered, transferred completely to a $100-\mathrm{mL}$ measuring flask and 
completed with water to the mark with distilled water. Ten $\mathrm{mL}$ of the solution was transferred into a $100-\mathrm{mL}$ measuring flask, $10 \mathrm{~mL}$ of $1 \times 10^{-2} \mathrm{~mol} \mathrm{~L}^{-1}$ sodium sulphate was added and completed with water to the mark. The final concentration was $10 \mathrm{mg} \mathrm{mL} \mathrm{m}^{-1}$. The concentration of phenobarbitone in the synthetic mixture was assayed using the proposed methods.

\section{Validation of new sensors}

The relation between the average potential and the measured concentration of new sensors is logarithmic, according to the Nernstian equation:

$$
E=E^{0}-S \log \text { [concentration] }
$$

where $E$ is the electrode potential, $E^{0}$ is the standard electrode potential, and $S$ is the slope. Validation was performed as indicated by the IUPAC guidelines (24). Lower limit of detection $(L O D)$ and lower limit of quantification $(L O Q)$ were calculated according to IUPAC (24), $L O D$ was the cross-point of two extrapolated fitted lines (the medium and the lowest one of $E v s$. log concentration curve) of the calibration function, whereas limit of quantification $(L O Q)$ was $3.3 \times L O D$.

Accuracy and precision. - Accuracy of the phenobarbitone assay was ascertained by addition of a known amount of phenobaritone into a pure solution. Percent accuracy was calculated as the closeness of the found to added concentrations.

On the other hand, precision was expressed as RSD in \%. The precision of the developed methods was examined by carrying out the analysis during the day and over three different days. The five replicate results were used for both accuracy and precision during intra- and inter-day testing.

The analysis of phenobarbitone by two different operators and two different instruments on diverse days was carried out to evaluate the intermediate precision of the proposed sensors.

\section{RESULTS AND DISCUSSION}

\section{Optimization of PVC membrane sensor composition}

Phenobarbitone is one of the molecules that form an inclusion complex with cyclodextrin $(25,26)$. The ability to form a complex is a function of space of the phenobarbitone guest molecule and its suitability to fit with the cavity of cyclodextrin host (Fig. 2).

Ionic additive. - The role of TDMACl as an ionic additive, being composed of the large cationic moiety and small anion, to the sensing materials $(\beta-C D$ or $\gamma-C D)$ in the PVC membrane sensor is to reduce ionic interference and to lower electrical resistance of the membrane $(27,28)$. Therefore both selectivity and sensitivity of the membrane were enhanced.

Membrane plasticizer. $-\beta$ - and $\gamma$-CD ionophores, combined with different plasticizers, namely, DOP, DBS and $o$-NPOE to give different combinations, were studied. It is well 

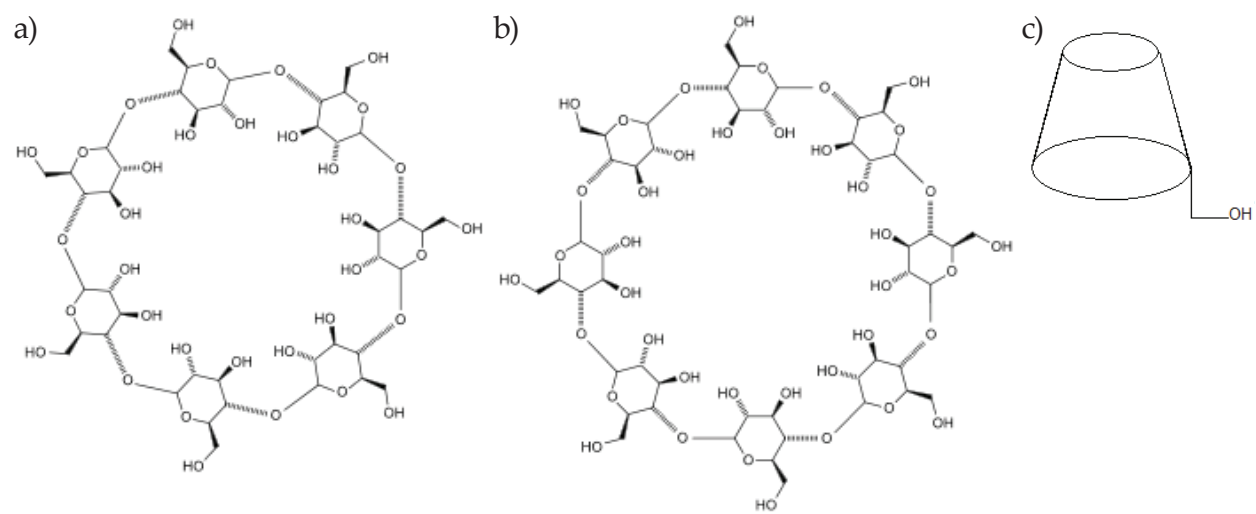

Fig. 2. Chemical structure of: a) $\beta$-cyclodextrine, b) $\gamma$-cyclodextrine, c) toroidal shape.

known that the construction of PVC-based membrane sensors requires the use of a plasticizer, which acts as a fluidizer allowing homogeneous dissolution and diffusion mobility of the ions inside the membrane (29).

The investigated sensors using either $\beta$ - or $\gamma$-cyclodextrin with two plasticizers (DOP or $o$-NPOE) were found appropriate. The best results were obtained with DOP. Hence, DOP was used as plasticizer when developing the proposed sensors.

\section{Performances and operating conditions}

The response time and operative lifetime were evaluated according to the IUPAC guidelines (24). The time required for the electrode potential to reach a constant reading $\pm 1.0 \mathrm{mV}$ is defined as the response time. The response time was found to be $25 \mathrm{~s}$ at $\geq 1 \times 10^{-3}$ mol L ${ }^{-1}$ phenobarbitone and $30 \mathrm{~s}$ at $\leq 1 \times 10^{-4} \mathrm{~mol} \mathrm{~L}^{-1}$ phenobarbitone.

Potential of the proposed sensors was recorded daily in the same solution and it was found stable for about $\pm 1.0 \mathrm{mV}$ for about one month. During this period, the potential slope was constant $(-59.0 \pm 0.5$ and $-62.0 \pm 0.5 \mathrm{mV}$ per decade, for sensors 1 and 2 , resp.). After that time (more than five weeks), the efficiency of the membrane decreased. Then the membrane sensor should have been replaced by a new section from the master membrane operating with high precision.

Effect of $\mathrm{pH}$. - The two created sensors were studied in the $\mathrm{pH}$ range 2-11. Fig. 3. shows the potential-pH profile of the phenobarbitone sensors. The potential-concentration profile demonstrated that the slopes of the proposed sensors were constant $(-59.1 \pm 1.0$ and $-62.0 \pm$ $1.0 \mathrm{mV}$ per decade) for sensor 1 and sensor 2, respectively, and the potential was found stable in the $\mathrm{pH}$ range 9-11 (Figs. 4). At $\mathrm{pH}$ lower than 7.4, there was an increase in potential due to the formation of phenylbarbituric acid $\left(\mathrm{p} K_{\mathrm{a}}=7.4\right)(30)$, while phenobarbitone anion existed in the $\mathrm{pH}$ range 9-11. Therefore this $\mathrm{pH}$ range was found to be most suitable for both sensors.

\section{Validation of the method}

Analytical performances of the sensors are shown in Tables I and II. Linear response was observed over the concentration range of $5 \times 10^{-6}$ to $1 \times 10^{-2}$ and $8 \times 10^{-6}$ to $1 \times 10^{-2} \mathrm{~mol} \mathrm{~L}^{-1}$ phenobarbitone for sensors 1 and 2, resp., in the $\mathrm{pH}$ range of 9.0 to 11.0. 
(a)

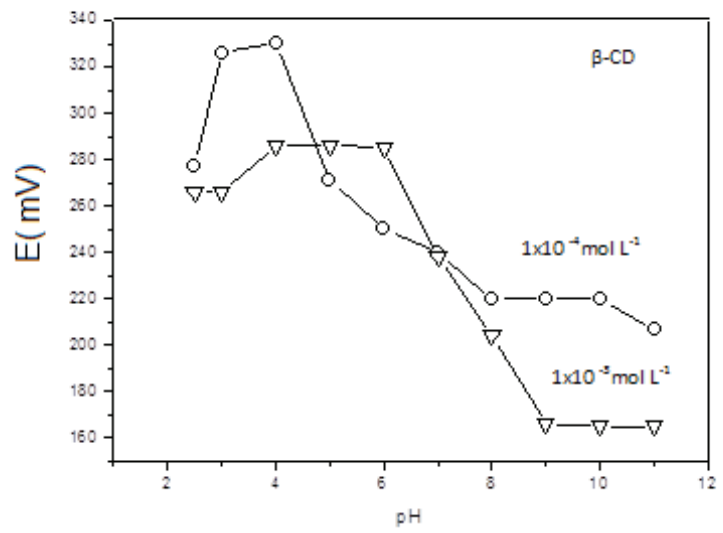

(b)

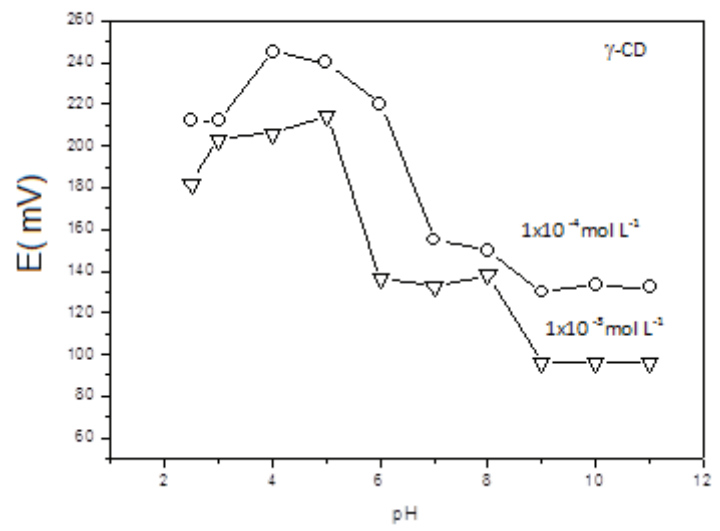

Fig. 3. $\mathrm{pH}$ profile of phenobarbitone sensors: a) sensor 1 with $\beta-C D$ and b) sensor 2 with $\gamma$-CD, using: $1 \times 10^{-3}$ (empty triangles) and $1 \times 10^{-4}$ (empty circles) $\mathrm{mol} \mathrm{L}^{-1}$ phenobarbitone.

The calibration line was defined as follows:

$$
E(\mathrm{mV})=-S \log [\text { phenobarbitone }]+\text { intercept }
$$

where $E$ is electrode potential, $S$ is the slope of the calibration graph $(-59.1 \pm 0.5$ and $-62.0 \pm 0.5 \mathrm{mV}$ per decade $)$ and intercept $(-15.1 \pm 0.5$ and $-51.6 \pm 0.5 \mathrm{mV})$ for sensors 1 and 2 , resp. (Fig. 4).

According to the IUPAC suggestion (24), the limit of detection (LOD) and limit of quantification $(L O Q)$ of the suggested procedures were found to be $1.5 \times 0^{-6}$ and $2.4 \times 10^{-6}$ mol L ${ }^{-1}$ and $5.0 \times 10^{-6}$ and $8.0 \times 10^{-6} \mathrm{~mol} \mathrm{~L}^{-1}$ phenobarbitone for sensors 1 and 2, respectively (Table I). $\beta$-cyclodextrin sensor showed a lower detection limit compared to $\gamma$-CD but both 
H. Alrabiah et al.: Ionophore-based potentiometric PVC membrane sensors for determination of phenobarbitone in pharmaceutical formulations, Acta Pharm. 66 (2016) 503-514.

Table I. Analytical performances of phenobarbitone-PVC sensors

\begin{tabular}{|c|c|c|}
\hline Parameter & Sensor 1 & Sensor 2 \\
\hline Phenobarbitione calibration range $\left(\mathrm{mol} \mathrm{L}^{-1}\right)$ & $3.6 \times 10^{-6}-1 \times 10^{-2}$ & $-62.0 \pm 0.5$ \\
\hline Working $\mathrm{pH}$ range & $9-11$ & $-51.6 \pm 0.5$ \\
\hline Calibration line slope ( $\mathrm{mV}$ per decade) & $-59.1 \pm 0.5$ & $-62.0 \pm 0.5$ \\
\hline Calibration line intercept $(\mathrm{mV})$ & $-15.1 \pm 0.5$ & $-51.6 \pm 0.5$ \\
\hline STEYX & 1.83 & 5.295 \\
\hline SE slope & 0.8 & 2.0 \\
\hline SE intercept & 3.0 & 9.0 \\
\hline Coefficient of determination $\left(R^{2}\right)$ & 0.999 & 0.996 \\
\hline$L O Q\left(\mathrm{~mol} \mathrm{~L}^{-1}\right)$ & $5.0 \times 10^{-6}$ & $8.0 \times 10^{-6}$ \\
\hline$L O D\left(\mathrm{~mol} \mathrm{~L}^{-1}\right)$ & $1.5 \times 10^{-6}$ & $2.4 \times 10^{-6}$ \\
\hline Response time $\left(1 \times 10^{-3} \mathrm{~mol} \mathrm{~L}^{-1}\right.$ phenobarbitone) $(\mathrm{s})$ & $25.0 \pm 0.5$ & $25.0 \pm 0.5$ \\
\hline
\end{tabular}

SE slope - standard error of the slope, SE intercept - standard error of the intercept

STEYX - standard error for the line of best fit, through a supplied set of $y$ - $(E, \mathrm{mV})$ and $x$ - (log concentration) values. Standard error of the predicted $y$-value for each $x$ in the regression.

$L O D, L O Q-$ limit of detection, quantification.

sensors showed a 100-fold lower detection limit compared to $2 \times 10^{-4} \mathrm{~mol} \mathrm{~L}^{-1}$ published by Lima et al. (18).

The influence of interferences was checked by measuring the potentiometric selectivity coefficients using the separate solutions method according to the IUPAC guidelines (24, 31). The selectivity coefficient $K_{A, B}^{p o t}$ was estimated from the following equation:

$$
-\log K_{A, B}^{p o t}=E_{1}-E_{2} / S
$$

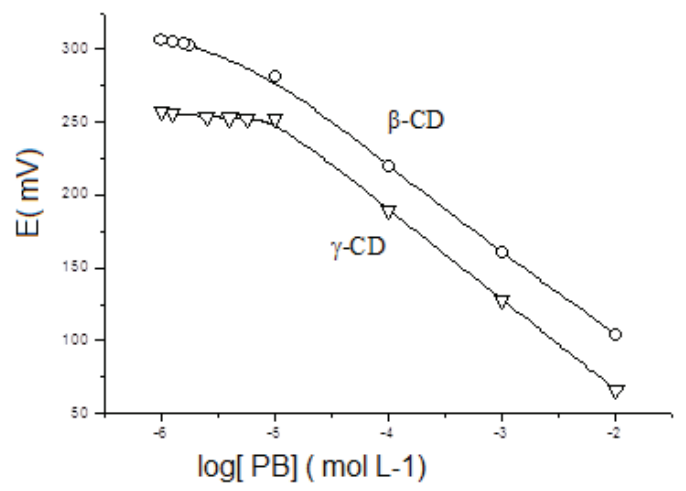

Fig. 4. Calibration curve of phenobarbitone membrane sensors (in $10^{-2} \mathrm{~mol} \mathrm{~L}^{-1}$ sodium sulphate). Calibration curve equations for $\beta$ - (sensor 1) and $\gamma$ - $C D$ (sensor 2) are: $y=-59.1 x-15.1$ and $y=-62.0 x-51.6$, respectively. 
H. Alrabiah et al.: Ionophore-based potentiometric PVC membrane sensors for determination of phenobarbitone in pharmaceutical formulations, Acta Pharm. 66 (2016) 503-514.

Table II. Selectivity coefficients of sensors 1 and 2 for some interfering species

\begin{tabular}{lll}
\hline Interfering species, B & $K_{P B, B}^{P o t}$ & $K_{P B, B}^{P o t}$ \\
& Sensor 1 & Sensor 2 \\
\hline $\mathrm{Na}^{+}$ & $3.0 \times 10^{-3}$ & $2.4 \times 10^{-3}$ \\
$\mathrm{~K}^{+}$ & $3.0 \times 10^{-3}$ & $2.3 \times 10^{-3}$ \\
$\mathrm{Fe}^{2+}$ & $3.1 \times 10^{-3}$ & $2.5 \times 10^{-3}$ \\
$\mathrm{Ca}^{2+}$ & $3.1 \times 10^{-3}$ & $2.3 \times 10^{-3}$ \\
Acetate & $1.6 \times 10^{-3}$ & $2.6 \times 10^{-3}$ \\
Phosphate & $3.2 \times 10^{-3}$ & $6.8 \times 10^{-3}$ \\
Citrate & $3.2 \times 10^{-3}$ & $2.5 \times 10^{-3}$ \\
Benzoate & $3.18 \times 10^{-3}$ & $2.6 \times 10^{-3}$ \\
Caffeine & $3.2 \times 10^{-3}$ & $3.0 \times 10^{-3}$ \\
Magnesium stearate & $4.46 \times 10^{-3}$ & $9.1 \times 10^{-3}$ \\
Glucose & $4.43 \times 10^{-3}$ & $9.2 \times 10^{-3}$ \\
Lactose monohydrate & $4.41 \times 10^{-3}$ & $9.1 \times 10^{-3}$ \\
Starch & $4.42 \times 10^{-3}$ & $9.2 \times 10^{-3}$ \\
Microcrystalline cellulose & $4.45 \times 10^{-3}$ & $9.1 \times 10^{-3}$ \\
\hline
\end{tabular}

$\mathrm{PB}$ - phenobarbitone

Table III. Determination of phenobarbitone using the proposed PVC membrane sensors

\begin{tabular}{lcc}
\hline \multirow{2}{*}{$\begin{array}{l}\text { Phenobarbitone added } \\
\left(\mu \mathrm{g} \mathrm{mL}^{-1}\right)\end{array}$} & \multicolumn{2}{c}{ Model recovery $(\% \pm \mathrm{RSD})^{\mathrm{a}}$} \\
\cline { 2 - 3 } 2.54 & Sensor 1 & Sensor 2 \\
25.42 & $102.7 \pm 3.9$ & $101.1 \pm 3.3$ \\
254.21 & $98.2 \pm 2.5$ & $102.0 \pm 2.0$ \\
2542.1 & $98.2 \pm 2.0$ & $97.4 \pm 1.5$ \\
\hline
\end{tabular}

${ }^{\mathrm{a}} n=6$

where $E_{1}$ is the potential measured in the phenobarbitone solution, $E_{2}$ is the potential measured in the solution of the interfering species and $S$ is the slope of the developed sensor. The assay was performed for several species such as benzoate, caffeine, lactose, starch, magnesium stearate, microcrystalline cellulose, etc. The results are presented in Table II. They show that the selectivity coefficient values were low $\left(1.6 \times 10^{-3}-9 \times 10^{-3}\right)$, indicating selectivity of the proposed sensors.

Accuracy and precision were examined at $2.54 \mu \mathrm{g} \mathrm{mL}^{-1}\left(1 \times 10^{-5} \mathrm{~mol} \mathrm{~L}^{-1}\right)$ of phenobarbitone sodium during a day and on three different days. The within-day recovery was 97.4 and $101.1 \%$, while the inter-day recovery was 97.0 and $100.0 \%$ for sensors 1 and 2, respec- 
tively. On the other hand, intra-day precision RSD for five replicates was 3.0 and $2.1 \%$ for sensors 1 and 2, respectively, while the inter-day imprecision was 3.2 and $2.5 \%$ for sensors 1 and 2 , respectively.

Analyses of phenobarbitone done by two different operators on two diverse instruments on three different days gave RSD lower than $3.5 \%$ as a measure of intermediate precision. Preliminary investigation of the proposed method under different conditions indicated that the suggested procedures are fairly robust and the only factor that must be controlled is the $\mathrm{pH}$ of the measuring medium, which should be in the range of 9 to 11 .

\section{Application of phenobarbitone sensors}

The analyses of model phenobarbitone solutions $\left(2.0-2542.1 \mu \mathrm{g} \mathrm{mL^{-1 } )}\right.$ with the suggested sensors indicate high model precision and accuracy of both sensors. The obtained results are displayed in Table III. The recovery ranged 98.0-102.7 and 98.0-101.1 \% for sensors 1 and 2, respectively. RSD was in the range of 1.8-3.9 and 1.4-3.3\% for sensors 1 and 2 , respectively.

Recovery of a known amount of phenobarbitone in synthetic laboratory powder was also checked with the proposed sensors. Recovery values of 98.3 and $98.8 \%$ with RSD of 1.9 and $3.0 \%$ for sensors 1 and 2, respectively were found. This was compared with the British pharmacopoeia (32) method, which showed an avarge recovery of $98.0 \%$ with th RSD value of $2.3 \%$. On the other hand, determination of phenobarbitone in the injection solution exhibited recovery of 99.0 and $98.6 \%$ with RSD of 2.0 and $3.2 \%$, compared to the reference method with an avarge recovery of $98.5 \%$ and RSD of $1.5 \%$. The obtained results are presented in Table IV.

The data listed in Table IV shows good agreement with the reference method (32), with experimental $F$ values for both sensors and both formulations lower than the tabulated value (33). Comparison between the experimental means for the two methods for $p$ $=0.05$ and $n=6$ was carried out. It was found that $t$ for both sensors and for both formulations was lower than the theoretical value (33). This data has proven that the results obtained by both semsors are of comparable precision and accuracy to that of the reference method.

Table IV. Determination of phenobarbitone in some pharmaceutical formulations using the membrane sensors

\begin{tabular}{|c|c|c|c|c|c|c|c|c|c|c|c|}
\hline \multirow{3}{*}{$\begin{array}{l}\text { Formula- } \\
\text { tion }\end{array}$} & \multirow{3}{*}{$\begin{array}{l}\text { Pheno- } \\
\text { bar- } \\
\text { bitone } \\
\text { dose }\end{array}$} & \multicolumn{4}{|c|}{ Proposed method } & \multirow{2}{*}{\multicolumn{2}{|c|}{$\begin{array}{l}\text { British Pharmaco- } \\
\text { poeia (ref. } 32 \text { ) }\end{array}$}} & \multicolumn{2}{|c|}{$F$-test } & \multicolumn{2}{|c|}{$t$-test } \\
\hline & & \multicolumn{2}{|c|}{ Sensor 1} & \multicolumn{2}{|c|}{ Sensor 2} & & & \multirow{2}{*}{$\begin{array}{c}\text { Sensor } \\
1\end{array}$} & \multirow{2}{*}{$\begin{array}{c}\text { Sensor } \\
2\end{array}$} & \multirow{2}{*}{$\begin{array}{c}\text { Sensor } \\
1\end{array}$} & \multirow{2}{*}{$\begin{array}{l}\text { Sensor } \\
2\end{array}$} \\
\hline & & Found & RSD (\%) & Found & RSD (\%) & Found & RSD (\%) & & & & \\
\hline Synthetic ${ }^{a}$ & $10 \mathrm{mg}$ & $9.93 \mathrm{mg}$ & 1.9 & $9.88 \mathrm{mg}$ & 3.0 & $9.8 \mathrm{mg}$ & 2.3 & 1.46 & 1.74 & 0.41 & 0.52 \\
\hline Injection $^{b}$ & $\begin{array}{c}200 \\
\mathrm{mg} \mathrm{mL}^{-1}\end{array}$ & $\begin{array}{c}198 \\
\mathrm{mg} \mathrm{mL}^{-1}\end{array}$ & 2.0 & $\begin{array}{c}197.2 \\
\mathrm{mg} \mathrm{mL}^{-1}\end{array}$ & 3.2 & $\begin{array}{c}197 \\
\mathrm{mg} \mathrm{mL}^{-1}\end{array}$ & 1.5 & 1.67 & 4.31 & 0.5 & 0.07 \\
\hline
\end{tabular}

\footnotetext{
${ }^{\text {a }}$ Laboratory prepared synthetic tablet.

${ }^{\mathrm{b}}$ Phenobarbital sodium injection $200 \mathrm{mg} \mathrm{mL}^{-1}$ (BDH, UK).

Tabulated values of $F$ and $t$ are 4.3874 and 2.8 for $p=0.05$ and $n=6$, respectively.
} 


\section{CONCLUSIONS}

Two PVC membrane sensors for the assay of phenobarbitone were constructed and optimized. The developed sensors used $\beta$ - or $\gamma$ - cyclodextrin as a neutral ionophore, dioctyl phthalate as a plasticizer and tridodecylmethylammonium chloride as a cationic excluser. Both sensors show good accuracy and precision in the $\mathrm{pH}$ range 9-11 and are of comparable performances. Our sensors show a wider linear range and a lower limit of detection compared to those reported in the literature (18). Sensor 1 shows higher sensitivity and wider dynamic range compared to sensor 2.

The suggested sensors offer the advantages of high sensitivity and fast response and could be used for the determination of phenobarbitone in its formulations.

Acknowledgements. - The authors express their gratitude to the Deanship of Scientific Research at King Saud University for funding the work through the research group project No. RGP-1436-024.

\section{REFERENCES}

1. Martindale: The Complete Drug Reference, $32^{\text {nd }}$ ed. (Ed. K. Parfitt), Pharmaceutical Press, London 1999.

2. N. B. Ilangaratne, N. N. Mannakkara, G. S. Bell and J. W. Sander, Phenobarbital: missing in action, Bull.World Health Org. 90 (2012) 871A-871A; DOI: 10.2471/BLT.12.113183.

3. M. J. Brodie and P. Kwan, Current position of phenobarbital in epilepsy and its future, Epilepsia 53 (2012) 40-46; DOI: 10.1111/epi.12027.

4. A. El-Gindy, HPLC and chemometric assisted spectrophotometric methods for simultaneous determination of diprophylline, phenobarbitone and papaverine hydrochloride, Farmaco 60 (2005) 745-753; DOI: 10.1016/j.farmac.2005.06.002.

5. X. Li, L. Niu, X. He and Z. Song, Determination of phenobarbital in human urine and serum using flow injection chemiluminescence, Biochemistry (Moscow) Suppl. Series B: Biomed. Chem. 5 (2011) 184-187; DOI: 10.1134/S1990750811020077.

6. C. M. Monzón, M. R. Delfino, Jr., M. del C. Sarno and, M. R. Delfino, Phenobarbital in pharmaceutical tablets by modified conductimetrical analysis, J. Arg. Chem. Soc. 96 (2008) 101-110.

7. J. B. Raoof, M. Baghayeri and R. Ojani, A high sensitive voltammetric sensor for qualitative and quantitative determination of phenobarbital as an antiepileptic drug in presence of acetaminophen, Colloid Surface B 95 (2012) 121-128; DOI: 10.1016/j.colsurfb.2012.02.038.

8. M. Vosough, S. Ghafghazi and M. Sabetkasaei, Chemometrics enhanced HPLC-DAD performance for rapid quantification of carbamazepine and phenobarbital in human serum samples, Talanta 119 (2014) 17-23; DOI: 10.1016/j.talanta.2013.10.026.

9. A. Serralheiro, G. Alves, A. Fortuna, M. Rocha and A. Falcão, First HPLC-UV method for rapid and simultaneous quantification of phenobarbital, primidonephenytoin, carbamazepine, carbamazepine-10, 11-epoxide, 10,11-trans-dihydroxy-10,11-dihydrocarbamazepine, lamotrigine, oxcarbazepine and licarbazepine in human plasma, J. Chromatogr. B 925 (2013) 1-9; DOI: 10.1016/j. jchromb.2013.02.026.

10. T. Villén and I. Petters, Analysis of barbiturates in plasma and urine using gas chromatography without prior derivatization, J. Chromatogr. A 258 (1983) 267-270; DOI: 10.1016/S0021-993(01)90686-7.

11. W. Chow and B. Caddy, Separation of underivatised barbiturates by capillary column gas chromatography: preparation of medium polar polymethylsiloxane columns to optimize selectivity, J. Chromatogr. A 318 (1985) 255-268; DOI: 10.1016/S0021-9673(01)90686-7. 
12. H. Zhao, L. Wang, Y. Qiu, Z. Zhou, X. Li and W. Zhong, Simultaneous determination of three residual barbiturates in pork using accelerated solvent extraction and gas chromatography-mass spectrometry, J. Chromatog. B 840 (2006) 139-145; DOI: 10.1016/j.jchromb.2006.05.002.

13. M. Iwai, H. Hattori, T. Arinobu, A. Ishii, T. Kumazawa, H. Noguchi, H. Noguchi, O. Suzuki and H. Seno, Simultaneous determination of barbiturates in human biological fluids by direct immersion solid-phase microextraction and gas chromatography-mass spectrometry, J. Chromatogr. B 806 (2004) 65-73; DOI: 10.1016/j.jchromb.2006.05.002.

14. A. Kadi, M. Hefnawy, S. Julkhuf, M. Abounassif, G. Mostafa, M. G. Kassem, S. Attia and A. AlGhamdi, Sample stacking microemulsion electrokinetic capillary chromatography induced by reverse migrating pseudostationary phase for the quantification of phenobarbital and its p-hydroxyphenobarbital metabolite in rat urine, Analyst 136 (2011) 2858-2865; DOI. 10.1039/C0AN00768D.

15. M. T. Ragab, M. K. A. El-Rahman, N. K. Ramadan, N. A. El-Ragehy and B. A. El-Zeany, Novel potentiometric application for the determination of pantoprazole sodium and itopride hydrochloride in their pure and combined dosage form, Talanta 138 (2015) 28-35; DOI: 10.1016/j.talanta.2015.01.045.

16. M. Khater, H. Hassib, Y. Issa and S. Mohammed, Surface morphology changes of polymer membrane and carbon paste sertraline sensors, Talanta 134 (2015) 546-553; DOI: 10.1016/j.talanta.2014.11.018.

17. M. M. Hefnawy, A. M. Homoda, M. A. Abounassif, A. M. Alanazi, A. Al-Majed and G. A. Mostafa, Potentiometric determination of moxifloxacin in some pharmaceutical formulation using PVC membrane sensors, Chem. Cent. J. 8 (2014) 59; DOI: 10.1186/s13065-014-0059-y.

18. J. L. Lima, M. C. B. Montenegro and A. R. Da Silva, A phenobarbital ion-selective electrode without an inner reference solution, and its application to pharmaceutical analysis, J. Pharm. Biomed. Anal. 8 (1990) 701-704; DOI: 10.1016/0731-7085(90)80106-Y.

19. H. AlRabiah, M. A. Abounassif, A. Al-Majed and G. A. E. Mostafa, Comparative investigation of $\beta$ - and $\gamma$-cyclodextrin as ionophores in potentiometric based sensors for naltrexone, Int. J. Electrochem. Sci. 11 (2016) 4930-4942; DOI: 10.20964/2016.06.10.

20. K.-H. Frömming and J. Szejtli, Cyclodextrins in Pharmacy, Springer Science \& Business Media, Budapest-Berlin 1993.

21. R. Challa, A. Ahuja, J. Ali and R. Khar, Cyclodextrins in drug delivery: an updated review, AAPS PharmSciTech. 6 (2005) E329-E357.

22. S. S. Hassan and S. A. Marzouk, A novel ferroin membrane sensor for potentiometric determination of iron, Talanta 41 (1994) 891-899; DOI: 10.1016/0039-9140(94)E0042-P.

23. A. Carggs, G. Moody and J. Tomas, PVC matrix membrane ion-selective electrodes, J. Chem. Educ. 51 (1974) 541-544; DOI: 10.1021/ed051p541.

24. R. P. Buck and E. Lindner, Recommendations for nomenclature of ion selective electrodes (IUPAC Recommendations), Pure Appl. Chem. 66 (1994) 2527-2536; DOI: 10.1351/pac199466122527.

25. A. Lopata, F. Darvas, Á. Stadler-Szóke and J. Szejtli, Quantitative structure-stability relationships among inclusion complexes of cyclodextrins I: Barbituric acid derivatives, J. Pharm. Sci. 74 (1985) 211-213; DOI: 10.1002/jps.2600740223.

26. K. Csabai, T. Cserháti and J. Szejtli, Interaction of some barbituric acid derivatives with hydroxypropyl- $\beta$-cyclodextrin, Int. J. Pharm. 91 (1993) 15-22; DOI: 10:1016/0378-5173(93)90416-D.

27. R. Eugster, P. M. Gehrig, W. E. Morf, U. E. Spichiger and W. Simon, Selectivity-modifying influence of anionic sites in neutral-carrier-based membrane electrodes, Anal. Chem. 63 (1991) 22852289; DOI: 10.1021/ac00020a017.

28. E. Bakker and E. Pretsch, Modern potentiometry, Angew. Chem. Int. Ed. 46 (2007) 5660-5668; DOI: 10.1002/anie.200605068. 
29. M. B. Gholivand, M. Mohammadi, M. Khodadadian and M. K. Rofouei, Novel platinum (II) selective membrane electrode based on 1,3-bis(2-cyanobenzene) triazene, Talanta 78 (2009) 922-928; DOI: 10.1016/j.talanta.2008.12.070.

30. A. C. Moffat, M. D. Osselton, B. Widdop and J. Watts (Eds.), Clarke's analysis of Drugs and Poisons, in Pharmaceuticals, Body Fluids and Postmortem Material, Vol. 1., Pharmaceutical Press, London 2004.

31. Y. Umezawa, P. Bühlmann, K. Umezawa, K. Tohda and S. Amemiya, Potentiometric selectivity coefficients of ion-selective electrodes. Part I. Inorganic cations (technical report), Pure Appl. Chem. 72 (2000) 1851-2082; DOI: 10.1351/pac200072101851.

32. British Pharmacopoeia, Stationery Office, London 2005, Volume II, pp. 1550.

33. J. N. Miller and J. C. Miller, Statistics and Chemometrics for Analytical Chemistry, $5^{\text {th }}$ ed., Pearson Education Limited, Harlow (UK) 2005. 